\title{
Cooperação Judicial Penal e Integração Regional: TRATAMENTO Normativo E Institucional na União Europeia E no Mercosul
}

\author{
Lucas Tavares Mourão* \\ Jamile Bergamaschine Mata Diz**
}

\begin{abstract}
1 Introdução. 2 A cooperação judicial como instrumento de aprofundamento da integração. $3 \mathrm{~A}$ formação e o desenvolvimento dos mecanismos de cooperação judicial em matéria penal na União Europeia. 4 O Mercosul e a cooperação judicial penal: breve aproximação. 5 Conclusão. Referências
\end{abstract}

\section{RESUMO}

Há muito já se nota que um país que atue isolado no cenário global está fadado a mergulhar em crises contornáveis apenas mediante uma ação integrada dos diversos agentes internacionais. Dentre os problemas que surgem no espectro mundial hodierno, há aqueles que atingem a esfera penal além-fronteiras. Nessa esteira, o presente trabalho busca fazer um levantamento comparativo dos mecanismos de cooperação judiciária penal no âmbito da União Europeia e do Mercosul. Com o crescimento dos níveis de integração, houve o aumento no intercâmbio de pessoas, mercadorias e serviços, alinhado à progressiva supressão de fronteiras, o que trouxe o indesejável crescimento da criminalidade transfronteiriça. Destarte, os países que compõem um sistema de integração se viram obrigados a adotar políticas convergentes para reprimir os delitos interestatais e evitar as impunidades. A conclusão a que se chega é de que, apesar dos relevantes avanços já apresentados, as instabilidades e discrepâncias ainda existentes entre os membros de um mesmo processo de integração impedem uma cooperação mais eficaz, o que constitui sério problema, haja vista a crescente onda de criminalidade transnacional.

Palavras-chave: Integração. Cooperação Penal. Mercosul. União Europeia.

* Advogado em Belo Horizonte/MG. Especialista em Direito Constitucional pelo Instituto pelo Desenvolvimento Democrático - Belo Horizonte/MG. E-mail: lucastmourao@gmail.com

** Catedrática Jean Monnet de Direito Comunitário. Professora da Faculdade de Direito da Universidade Federal de Minas Gerais. Professora da Universidade de Itaúna-MG Brasil. Professora da FNH/BH. Doutora em Direito Público/Direito Comunitário pela Universidad Alcalá de Henares - Madrid. Assessora Jurídica do Setor de Assessoria Técnica Secretaria do MERCOSUL - Montevidéu (período: 2008-2009). Master em Instituciones y Políticas de la UE - UCJC/Madrid. E-mail: jmatadiz@yahoo.com.br. 


\section{INTRODUÇÃO}

Busca-se, neste trabalho, analisar o fenômeno da integração, em particular a cooperação judicial como elemento para o fortalecimento da associação interregional. Nesse sentido, objetiva-se demonstrar como o desenvolvimento da cooperação entre os sistemas judiciais dos processos de integração entre os Estados do Cone Sul se reflete na criação de um sistema próprio de especial relevância para o cumprimento de decisões, atos e demais tipos de instrumentos gerados no âmbito judicial. Assume relevo, em especial, a análise de como a capacidade operativa e jurídica desse sistema pode dar ensejo - ou não - à concretização das finalidades que os Estados colocaram no contexto do impulso integrador.

Nesse viés, o estudo delineará a formação dos processos de integração sob uma ótica instrumental, baseada nos distintos mecanismos de cooperação gerados pela União Europeia, em maior medida, e pelo Mercosul. Atenção especial deve ser dedicada aos instrumentos criados pelo sistema europeu como marco de referência para os demais processos integradores. Esse destaque se deve à potencialidade que guarda a União Europeia como união monetária e econômica que ultrapassa os limites meramente comerciais que, até então, vinham sendo realizados pelos Estados em suas distintas relações exteriores. Uma abordagem crítica, tal como empreendida neste trabalho, tem o condão de colocar em discussão a importância da cooperação judicial para a integração regional, além de reforçar a necessidade de aprimoramento institucional e procedimental, de modo a efetivamente alcançar mecanismos eficientes, céleres e próprios para a concretização da justiça, e que se torne uma realidade cotidiana na vida dos Estados e de seus cidadãos.

A metodologia do trabalho deverá centrar-se nos aspectos principais estabelecidos para uma pesquisa interdisciplinar que envolve temas de direito internacional e seu tratamento pelo direito da integração, em razão especialmente do caráter específico e singular da análise de um sistema jurídico marcado por um tipo determinado de relação interestatal, e que envolve temas relativos à cooperação judicial entre os atores. Neste sentido, devem-se utilizar métodos que permitam analisar a evolução da construção da institucionalidade compartilhada mediante a criação de sistemas comuns de decisão. Os métodos histórico e indutivo permitirão estabelecer as premissas conceituais e práticas aplicadas ao tema da institucionalidade no marco do processo de criação da própria associação interestatal sul-americana.

\section{A COOPERAÇÃO JUDICIAL COMO INSTRUMENTO DE APROFUN- DAMENTO DA INTEGRAÇÃO}

Tem-se hoje, como se sabe, a presença de diversos processos de integração pelo globo, cada qual comportando a estrutura que lhe cabe, respeitando os limites econômicos, políticos, sociais e culturais dos Estados que os compõem e perseguindo fins que, embora possam ter uma origem comum, divergem se- 
gundo as ambições e as potencialidades de cada região. É o que se percebe ao se colocar de um lado a União Europeia e, de outro, processos de integração mais incipientes e menos aprofundados, como o NAFTA, a ALCA e, no meio do caminho, o Mercosul.

Nesse cenário de intensificação dos processos integracionistas, pergunta-se, o que significa o termo "cooperação", onde se enquadra e qual sua influência nas dinâmicas da integração?

Segundo Toffoli e Cestari1" "cooperação pressupõe trabalho conjunto, colaboração. É nesse sentido que toda e qualquer forma de colaboração entre Estados, para a consecução de um objetivo comum, que tenha reflexos jurídicos, denomina-se cooperação jurídica internacional”. Na mesma coletânea, ensina Nádia de Araújo (2008, p. 40) ser a cooperação jurídica internacional o intercâmbio internacional para o cumprimento extraterritoral de medidas processuais do Poder Judiciário de outro Estado.

Por sua vez, Galvão de Souza² asseverou com eficácia ser a cooperação jurídica internacional "o auxílio prestado entre nações soberanas, para que o processo iniciado, a iniciar-se ou findo em um Estado, possa ter seguimento com a realização de ato jurídico por órgão jurisdicional ou mesmo administrativo de outro Estado".

Segundo assevera o pesquisador da escola uruguaia, a cooperação reside na necessidade de os Estados aceitarem a aplicação da extraterritorialidade de atos e decisões judiciais como forma de garantir a realização da justiça sem depender do desenho geopolítico. Impedir-se-ia, assim, que as fronteiras internacionais se tornassem obstáculos intransponíveis à justiça.

Em outras palavras, a cooperação decorre da confiança das nações no processo jurisdicional que vai além das fronteiras nacionais, repercutindo em território alheio, "mas solidário na tutela da legalidade", nas palavras de Leonardo Araújo Abimorad ${ }^{3}$.

$\mathrm{Na}$ outra esfera, levanta-se a doutrina de $\mathrm{Mata}_{\mathrm{Diz}}{ }^{4}$, quando ensina que a aplicação de normas de integração ultrapassa a mera cooperação internacional, estipulando uma rede de instituições e seu próprio sistema legal.

Nesse sentido, Mariano e Mariano ${ }^{5}$ defendem que a integração regional é mais ampla que a cooperação, vez que pode resultar em novas unidades ou entidades políticas. Segundo esses autores, a integração atinge a sociedade como um todo, gerando interações que fogem ao controle estatal entre grupos de interesse e representantes das sociedades. Por outro lado, a cooperação pode ser uma estratégia contextualizada e ser abandonada de acordo com a conveniência, enquanto a integração é menos flexível.

Para Mata Diz e Penido Martins ${ }^{6}$, a integração é um estágio mais avançado, que pode ser alcançado a partir do desenvolvimento, por exemplo, da cooperação. Pode-se dizer de forma simplificada que a cooperação é um passo para o alcance da integração. 
Enquanto a integração é mais ampla e rígida, abrangendo a sociedade envolvida como um todo, o sistema de cooperação denota maior flexibilidade e especificidade em determinado aspecto, que pode ser transitório ou permanente.

A diferença entre as duas noções fica mais evidente quando tomamos como parâmetro a União Europeia, que é o processo de integração mais avançado e complexo da atualidade, abordando diferentes vertentes políticas, econômicas e sociais. Por outro lado, dentro do sistema formado pela integração, há diversas formas de cooperação firmadas entre uns e outros Estados soberanos, almejando objetivos específicos entre eles. É o caso, por exemplo, da cooperação em matéria penal.

\section{A FORMAC̣ÃO E O DESENVOLVIMENTO DOS MECANISMOS DE CO- OPERAÇÃ O JUDICIAL EM MATÉRIA PENAL NA UNIÃO EUROPEIA}

O Tratado de Nice, mantendo o que já predispunha o Tratado da União Europeia, ambos em seu art. 31, prevê que a Cooperação Judiciária visa, dentre outros, a facilitar e acelerar a cooperação entre os ministérios e as autoridades judiciárias dos Estados Membros.

A ideia é de assegurar a compatibilidade das regras aplicáveis em cada Estado Membro, prevenir os conflitos de competência e adotar progressivamente medidas que instaurem regras mínimas aos elementos constitutivos das infrações e às sanções aplicáveis frente a diversos campos da criminalidade.

Instituíram-se, para tanto, procedimentos específicos, tanto no plano formal, quanto no pessoal ou material. São procedimentos que visam às demandas de cooperação, as quais são destinadas a uma autoridade judiciária especificamente designada, em busca da execução de determinados atos.

Por certo, os pedidos de assistência ou cooperação europeus se integram em um procedimento judicial que tem por objetivo a repressão de uma infração, mas seu aspecto transnacional também lhes confere um aspecto político, em necessária observância às soberanias nacionais.

Em princípio, esse controle político pode representar um óbice à celeridade do procedimento de assistência mútua, pois conserva uma regra de transmissão indireta do pedido de assistência à autoridade judiciária pela via ministerial. Contudo, como a exemplo dos art. 694 e 695-1 do Código de Processo Penal Francês, há situações em que o pedido de auxílio é simplificado, frente à necessidade de reprimir as infrações mais graves. Nessas situações, privilegia-se o aspecto Judiciário em detrimento do diplomático.

Com o incremento do espaço Judiciário europeu, houve a criação de autoridades europeias nele envolvidas, o que é uma inovação essencial, já que configura uma medida de suma importância para um combate mais eficiente à criminalidade transfronteiriça. Trata-se das Equipes Comuns de Inquérito e do Eurojust. 
No que concerne às equipes comuns de inquérito, elas podem tanto intervir no Estado em que são compostas, quanto no estrangeiro. Suas condições de criação, contudo, não são unânimes entre os Estados; por exemplo, na França, sua criação está condicionada a um acordo prévio do Ministro da Justiça e ao consentimento dos Estados interessados, enquanto que na Espanha, a competência de sua instauração é do Ministro do Interior.

Na prática, as equipes são uma ferramenta resultante de acordos entre autoridades de variados Estados para conduzir em comum investigações relativas a infrações penais que tenham afetado esses países. Trata-se verdadeiramente de um trabalho de colaboração. O conjunto dos atos e das provas colhidos é válido nos procedimentos de todos os países parte no inquérito.

Vê-se, portanto, um engajamento baseado no reconhecimento mútuo. É este reconhecimento recíproco das decisões e das autoridades judiciárias que confere poderes aos agentes estrangeiros e facilita as perseguições. Portanto, diz-se que os objetivos primordiais das equipes é eliminar as fronteiras jurídicas e policiais, aproximar as autoridades judiciárias e evitar a sobrecarga dos modelos clássicos de cooperação

De outro lado, tem-se a Eurojust, que funciona como órgão da União Europeia dotado de personalidade jurídica e encarregado de facilitar a cooperação judiciária. Sua missão é lutar contra as formas graves de criminalidade transfronteiriça, permitindo a coleta, a gestão e o intercâmbio de informações.

Sua atuação é uma complementação da Rede Judiciária Europeia ${ }^{7}$, que é um canal de informações práticas entre as autoridades nacionais. A Eurojust completa igualmente o Organismo Europeu de Luta Contra a Fraude (OLAF), o qual consiste em uma autoridade administrativa, cuja missão é lutar contra a fraude aos interesses financeiros da União Europeia e investigar as violações de agentes e funcionários das comunidades. É frequente a participação do OLAF nas ações coordenadas pela Eurojust.

A Eurojust é, portanto, encarregada de promover e melhorar a coordenação e a cooperação entre as autoridades competentes dos Estados Membros da União Europeia em todos os inquéritos e perseguições relevantes de sua competência. Sua missão pode ser de coordenação e cooperação entre vários Estados Membros, mas também pode ser de suporte em inquéritos e perseguições que concernem tão somente a um Estado, individualmente.

No entanto, a Eurojust não tem competências próprias. Ela foi criada há doze anos como uma etapa importante rumo à criação de um Espaço de Liberdade, Segurança e Justiça, mas não detém a competência para ela própria efetuar atos de inquérito ou de perseguição. Não se trata de um parquet europeu, mas de uma ferramenta de cooperação para coordenar a ação das autoridades nacionais que investigam ou se engajam na perseguição. 
Em sua atuação, a Eurojust, por intermédio dos representantes nacionais, pode informar às autoridades nacionais o conhecimento de dados específicos e demandar-lhes que procedam à abertura de um inquérito ou que iniciem uma perseguição. Pode solicitar à autoridade de um Estado que denuncie as infrações às autoridades equivalentes de outro Estado Membro. Por fim, pode também solicitar que a autoridade instaure uma Equipe Comum de Inquérito.

Em linhas gerais, às principais autoridades envolvidas na cooperação interestatal, cumpre trazer à discussão as principais formas de cooperação em atividade na União Europeia. De início, cabe mencionar que a figura da extradição clássica foi perdendo sua expressividade nas relações entre os países do Velho Continente. Afinal, embora suas bases estejam voltadas a um sistema jurídico de colaboração internacional, não há um procedimento extradicional unificado, sendo a questão disciplinada pelo ordenamento interno de cada país.

Ao analisar o art. 2० da Convenção Europeia de Extradição, vê-se que podem dar causa à extradição todos os delitos punidos com uma pena ou medida de segurança privativa de liberdade com duração máxima não inferior a um ano. Já para o caso de execução de uma pena já aplicada, esta deve ter a duração mínima de quatro meses. Nesta última hipótese, a duração mínima é condição cumulativa com a prevista na primeira parte.

Pontos de maior polêmica da Convenção dizem respeito ao art. $3^{\circ}$, quando dispõe que quanto aos crimes políticos não poderá ser concedida a extradição, se o crime for dessa natureza, ou de natureza acessória a ela. Também o polêmico campo da extradição de nacionais, que é posta como uma faculdade das partes; no caso, é previsto que o Estado requerido que recusar a extradição de seu nacional deve, a pedido do Estado requerente, submeter o assunto às autoridades competentes em seu território, para que se instaure o procedimento criminal. ${ }^{8}$

Dos aspectos mais importantes da Convenção, contudo, é a determinação de que não será procedida à extradição se não houver garantia de que a pessoa solicitada seja julgada por tribunal que lhe assegure as garantias fundamentais, tanto processuais, quanto de proteção dos direitos de defesa. Para o Conselho Europeu, essas garantias, reconhecidas pela Convenção Europeia para Proteção dos Direitos do Homem e das Liberdades Fundamentais, podem motivar a recusa em extraditar alguém.

É ainda importante mencionar as Convenções de Bruxelas de 1995 e de Dublin de 1996, resultantes de uma política europeia de aumento da cooperação judiciária, em especial em matéria extradicional. No entanto, ambas foram quase totalmente substituídas pela decisão-quadro sobre o mandado de detenção europeu, sendo aplicadas somente nos casos em que este não pode ser utilizado. ${ }^{9}$

Sobre a primeira delas, a Convenção de Bruxelas de 1995, o mais importante a ser ressaltado é a introdução de um procedimento simplificado de entrega, que pode ser utilizado quando houver o consentimento do extraditando e a concordância do Estado requerido. Já a Convenção de Dublin de 1996 teve 
maior relevo ao derrogar o princípio da dupla incriminação ${ }^{10} \mathrm{em}$ relação a tipos penais específicos, desde que puníveis com pena restritiva de liberdade com pena máxima não inferior a um ano, com base na legislação do Estado requerente; e que a associação para o crime ou conspiração pela qual se requer a extradição tenham como finalidade a prática de um ou mais dos delitos previstos na Convenção Europeia sobre a Repressão do Terrorismo, de 1977.

Com o tempo, a extradição passou a ser um procedimento excepcional, utilizado apenas entre países que veem o sistema judicial de seus pares com desconfiança. É um sistema lento, custoso e produz resultados incertos, em razão da grande discricionariedade que tem o Estado requerido na sua análise. ${ }^{11}$ Tendo isso em vista, outras políticas vêm sendo exploradas, a exemplo do mandado de detenção europeu.

A Decisão-Quadro de 13 de junho de 2002 sobre o Mandado de Detenção Europeu trouxe um novo procedimento de entrega dos indivíduos procurados, com o objetivo de dar andamento aos procedimentos penais ou ao cumprimento de uma pena. O procedimento só se aplica, contudo, entre os Estado Membros da União Europeia, substituindo o procedimento clássico de extradição que, no entanto, subsiste em certos casos. Esse novo modelo trazido pela decisão-quadro é inteiramente judicial e visa principalmente a conceder mais celeridade aos processos de cooperação.

O mandado em referência corresponde à vontade de criar um sistema eficaz para substituir o procedimento clássico de extradição entre os Estados Membros da UE. Essa vontade foi concretizada após os atentados de 11 de setembro de 2001, com vistas a facilitar e a acelerar as perseguições. É instrumento de harmonização dos procedimentos dentro do espaço Judiciário europeu, para lutar contra a crescente criminalidade transnacional.

Cabe à autoridade judiciária a competência para endereçar à autoridade judiciária de outro Estado Membro o mandado de detenção, ou o executar sob sua demanda, o que revela um exemplo concreto de cooperação judiciária direta, com base no reconhecimento e no respeito mútuo.

Como dito antes, o mandado de detenção europeu é um procedimento de entrega aplicável unicamente entre os Estados Membros da UE, em substituição ao procedimento clássico de extradição. Quer dizer que um Estado não membro que demande a entrega de um indivíduo deve recorrer à extradição prevista em outras convenções internacionais, notadamente a Convenção do Conselho da Europa de 13 de dezembro de 1957, as regras de extradição do Acordo Schengen, dentre outras.

Entre os Estados Membros, o procedimento do mandado de detenção se aplica a certas condições relativas à infração. $\mathrm{O}$ mandado de detenção europeu pode ser emitido por fatos puníveis pela lei do Estado-Membro de emissão com pena ou medida de segurança privativa de liberdade de duração máxima não inferior a um ano, ou quando tiver sido decretada uma pena ou aplicada uma 
medida de segurança por sanções de duração não inferior a quatro meses. Quando as condições estão reunidas, o Estado Membro não tem, necessariamente, de adotar esse procedimento, podendo preferir a entrega do indivíduo segundo o Processo Simplificado de Extradição entre os Estados Membros da União Europeia, de 10 de março de 1995.

Pode-se utilizar, portanto, de um ou de outro meio entre os Estados Membros, e o procedimento de extradição ordinária para os Estados não membros, ou seja, os que não fazem parte da União Europeia.

Em matéria de extradição, é aplicado o Princípio da Dupla Incriminação, o que significa que é possível extraditar alguém, caso o fato pelo qual ele é perseguido for reprimido no Estado requerente e no requisitado. Esta regra permite uma harmonização das legislações penais dos Estados Membros. Não pode ser esquecida, contudo, a exceção apresentada pela Convenção de Dublin de 1996, abordada alhures.

No que pertine ao mandado de detenção, em princípio, o ato infracional no Estado de emissão também deve sê-lo no Estado de execução. Contudo, tal postulado não se aplica a alguns tipos de infração, desde que preencham duas condições: a primeira é de que os fatos sejam punidos pela lei do Estado de emissão com uma pena ou medida de segurança restritiva de liberdade superior ou igual a três anos; a segunda é de que os fatos façam parte das infrações consideradas como as mais graves.

Todavia, como dito em outro momento, a entrega dos indivíduos perseguidos pode ser recusada, desde que motivada. Os motivos que justificam a recusa se dividem em obrigatórios e facultativos e concernem, dentre outros, à entrega para perseguir ou punir alguém em razão de suas orientações políticas, ou para executar uma sanção contra uma pessoa nacional da parte requisitada. São motivos antigos que, tradicionalmente, impedem a extradição.

Aponta-se ser o procedimento do mandado de detenção inteiramente Judiciário, permitindo o envio da pessoa procurada de uma autoridade judiciária a outra, evitando a via diplomática. É meio mais simples e rápido que a extradição, mesmo a simplificada, e com duração média do procedimento muito inferior. Embora mais simples que a extradição, o mandado europeu é mais completo, o que o torna extremamente útil para lutar contra a delinquência, antes que desapareçam seus vestígios, sendo assim, portanto, etapa significativa rumo à elaboração do Espaço Judiciário Europeu.

Cumpre ainda abordar o ideário acerca da instauração de um Registro Criminal Europeu ${ }^{12}$.

É de longa data a necessidade de um registro criminal europeu ${ }^{13}$, mas esse instrumento não é ainda uma realidade. $O$ que existe são modelos similares, mas não centralizados, em que funciona uma cooperação judiciária com base em informações sobre o passado das pessoas perseguidas penalmente (Service do Casier Judiciaire National, 2013). 
A existência de um registro criminal é importante, sobretudo, para aplicar eventualmente as regras de reincidência e, assim, agravar a repressão. Sua necessidade se mostra patente para garantir a liberdade de circulação das pessoas, e em razão do aumento da criminalidade transfronteiriça.

O problema subsistente, contudo, é a diversidade entre os sistemas nacionais que efetuam os registros. A autoridade que centraliza as informações varia segundo o país, podendo ser Ministro da Justiça, Ministro do Interior, ou mesmo a polícia. Em alguns casos, todas as condenações são mencionadas, já em outros, apenas aquelas mais graves constam no sistema. Em alguns casos, decisões que absolvem o indivíduo do ato ilícito são inseridas; noutros, até mesmo decisões de autoridades administrativas são recolhidas. Há discrepância também quanto ao acesso à informação, que pode ser mais ou menos limitada às autoridades judiciárias, administrativas ou políticas. Por fim, outro obstáculo é a diferença concernente ao tempo necessário para a prescrição; enquanto que em alguns países ela jamais ocorre, em outros, ela é automática após determinado decurso de tempo. ${ }^{14}$

Afora a dificuldade de compreensão da informação recebida dentro do quadro de cooperação entre as autoridades judiciais, esse projeto falhou em razão das dificuldades para ser posto em prática. É um instrumento que necessitaria de assistência logística complexa, com sistemas de manutenção, estocagem e acesso a informações, o que geraria custos demasiadamente elevados. Ademais, as liberdades fundamentais estariam em risco, haja vista a ampla circulação de dados pessoais ${ }^{15}$.

Contudo, a ideia de um verdadeiro registro europeu persiste, mas limitado a certos domínios, como na luta contra o crime organizado, por exemplo.

Atualmente, há duas grandes iniciativas em nível europeu, que concernem à facilitação do intercâmbio de informações entre os registros nacionais e ao índex de pessoas condenadas. São sistemas mais leves, simples e baratos, em que a informação é conservada em nível nacional e transmitida à autoridade nacional, que a mantém. ${ }^{16}$

O primeiro caso, de facilitação de troca de informações, é uma modernização do sistema da Convenção Europeia de Cooperação de 1959, ou seja, a Comissão Europeia reviu certos pontos para acelerar a colaboração entre os nacionais. É o caso, por exemplo, da regra que impõe aos Estados Membros o dever de lançar em seus registros tão somente as condenações ocorridas no exterior.

Já o índex tem a função de permitir às autoridades judiciárias de um Estado que constatem em quais outras localidades o indivíduo já tenha sido condenado. O índex contém indicações mínimas sobre o estado civil e o país no qual a pessoa foi condenada, quando presente um mínimo de harmonização das informações. Esse índex deve ser alimentado pelos registros dos Estados Membros, dentro de um formato padronizado e podendo conter informações complementares como a qualificação dos fatos. 
Para além dos dois projetos supra mencionados, existe na prática uma interconexão de registros nacionais, mas somente entre quatro Estados: França, Alemanha, Bélgica e Espanha. Esse sistema permite a transmissão de informações entre as partes por meio de um servidor que recebe e centraliza as demandas e as informações. É um sistema inteiramente informatizado e que facilita a conservação dos dados relativos a condenações em cada Estado. Trata-se de uma modernização da ideia de 1959, com obtenção de dados de forma rápida, a partir de intercâmbio bilateral entre as partes. ${ }^{17}$

Por melhor que seja no momento, o exemplo existente entre os quatro membros tem muito a se aperfeiçoar. Ele exige um suporte único de comunicação de informações, assim como um apoio logístico para a transmissão de informações, visto existirem discrepantes diferenças jurídicas entre as partes, o que dificulta a exploração dos dados e das fichas de condenação. Para tanto, intervêm membros das autoridades judiciárias, assim como técnicos em informática e linguistas especializados em Direito Penal.

Não se trata de um verdadeiro registro criminal europeu, mas já é um modelo próximo do que se pretende com uma interconexão ampliada a todos os países membros.

\section{O MERCOSUL E A COOPERAÇÃO JUDICIAL PENAL: BREVE APRO- XIMAÇÃO}

Conforme acentua Nádia de Araújo, ${ }^{18}$ a legislação que regulamenta a cooperação jurídica internacional é fragmentada. No caso dos países membros do Mercosul, cuidam da cooperação jurídica internacional as normativas internas e os inúmeros diplomas de origem internacional, como convenções multilaterais, regionais e bilaterais.

Em se tratando de acordos multilaterais, há três convenções firmadas com a chancela da ONU, voltadas ao combate à criminalidade transnacional, que merecem destaque no presente estudo, em especial por terem sido incorporadas pelos Estados componentes do Mercosul. São elas as Convenções de Viena, Palermo e Mérida.

A primeira delas, a Convenção das Nações Unidas sobre o Tráfico Ilícito de Entorpecentes e Substâncias Psicotrópicas, aprovada em Viena no ano de 1988, tinha como principal objetivo o fortalecimento dos meios jurídicos para fomentar a cooperação internacional em matéria penal, com vistas ao combate às atividades criminosas internacionais decorrentes do tráfico ilícito de drogas.

Uma importante consequência dessa Convenção foi o compromisso internacional assumido pelos países de criminalizar a lavagem de dinheiro decorrente do tráfico de drogas. Desde então, os países passaram a editar leis sobre esse tema. ${ }^{19}$

Já no ano de 1999, foi celebrada em Palermo, Itália, a Convenção das Nações Unidas contra o Crime Organizado Transnacional, entrando em vigor em $2003^{20}$. 
É o principal mecanismo existente, no cenário internacional, atinente a crimes de grande complexidade, cometidos por um grupo criminoso organizado, com área de abrangência global.

A Convenção de Palermo estabelece que os Estados devem criminalizar diversas condutas que estão intimamente ligadas ao crime organizado internacional, tais como a participação em grupo criminoso organizado, corrupção e lavagem de dinheiro, sendo este último o objetivo global para a manutenção da segurança internacional.

Por fim, aborda-se a Convenção das Nações Unidas contra a Corrupção de 2003, firmada em Mérida (México), que entrou em vigor internacionalmente em dezembro de 2005. Consiste no primeiro tratado multilateral direcionado para as questões decorrentes da corrupção, cujo conteúdo permite embasar um pedido de cooperação internacional ou de recuperação de ativos ${ }^{21}$, objetivando "a promoção, a facilitação e o apoio à cooperação internacional e à assistência técnica na prevenção e na luta contra a corrupção, incluída a recuperação de ativos", conforme disposto no artigo primeiro. ${ }^{22}$

Feita essa análise das principais Convenções regulamentadoras da cooperação penal em nível internacional ${ }^{23}$, passa-se a um estudo dos acordos em nível regional, em especial àqueles que são adstritos ao âmbito dos membros do Mercosul, exclusivamente. Referidos textos são primeiramente utilizados como substrato para embasar um pedido de cooperação internacional entre os Estados componentes do grupo.

Salienta-se a importância dos tratados regionais frente aos multilaterais, pois que estes dizem respeito a condutas específicas, sendo enquadrados como "criminalizantes" (tipificam as condutas de tráfico ilícito de entorpecentes, crime organizado transnacional e corrupção, por exemplo). Por outro lado, os tratados regionais são generalistas. ${ }^{24}$

Em âmbito mais restrito que as Convenções acima trabalhadas, trazem-se à baila os frutos da Organização dos Estados Americanos (OEA), em especial a Convenção Interamericana sobre Assistência Mútua em Matéria Penal, feita em maio de 1992 na cidade de Nassau, Bahamas, e vigente nos Estados Partes do Mercosul.

A Convenção da OEA, que se baseia na Carta da Organização dos Estados Americanos, estabelece como propósito essencial dos Estados americanos buscar a solução dos problemas políticos, jurídicos e econômicos que surgirem entre os membros. Salienta que a adoção de regras comuns no campo da assistência mútua, em matéria penal, contribuirá para esse propósito. ${ }^{25}$

Apresenta ainda, em seu artigo primeiro, que os Estados-Partes se comprometem a prestar assistência mútua em matéria penal em investigações, processos e procedimentos referentes a delitos cujo conhecimento seja da competência do Estado requerente no momento em que solicitar a assistência. 
Há, ainda, outras formas de cooperação além da efetuada por meio de tratados. É o exemplo, no âmbito da OEA, da Rede Hemisférica de Intercâmbio de Informações para o Auxílio Jurídico Mútuo em Matéria Penal e de Extradição, fruto da deliberação da V Reunião de Ministros da Justiça da OEA, realizada em 2004, na cidade de Washington (EUA). Nela, foi estabelecido um mecanismo de correio eletrônico seguro que possibilita a troca de documentos e o compartilhamento de espaços de trabalho destinados ao desenvolvimento conjunto de assuntos de interesse comum. ${ }^{26}$

Ainda no âmbito latino americano, existe a Rede Ibero-Americana de Cooperação Jurídica (IberRede), instituída em 2004, com objetivo de aperfeiçoar a cooperação jurídica em matéria civil e penal entre os países membros, bem como estabelecer sistema de informações sobre seus diferentes sistemas jurídicos. A IberRede é composta pelos Estados que participam das Cúpulas Ibero-Americanas de Chefes de Estado e de Governo, que, além dos países latino americanos, engloba também Portugal e Espanha. ${ }^{27}$

Enfim, cabe apresentar os acordos firmados estritamente entre os membros do Mercosul com vistas à cooperação jurídica em matéria penal.

Em primeiro lugar, cumpre mencionar o Protocolo de Cooperação e Assistência Jurisdicional em Matéria Cível, Comercial, Trabalhista e Administrativa, feito em Las Lenãs no ano de 1992. Dito instrumento possibilitou o requerimento de homologação de sentença no Mercosul, via carta rogatória. ${ }^{28}$

Esse protocolo, no entendimento de Cervini e Tavares ${ }^{29}$, contém uma isolada, mas relevante disposição, que representa um verdadeiro marco de avanço dentro da cooperação penal. Trata-se do artigo 18 que, em sua parte final, "abarca também o reconhecimento e execução de sentenças ditadas em matéria de reparação de danos e restituição de bens pronunciados em jurisdição penal”.

Outro tratado que vale a pena mencionar é o Acordo de Assistência Jurídica Mútua em Assuntos Penais, celebrado entre Brasil e Uruguai, no ano de 1992, em Montevidéu. A relevância deste instrumento reside em prever uma cooperação jurídica penal destinada a instruir investigação ou um processo penal, além de se constituir verdadeiro embrião para o Protocolo de São Luis, de 1996. ${ }^{30}$

O Protocolo de Assistência Jurídica Mútua em Assuntos Penais do Mercosul, firmado na cidade argentina de São Luis, em 1996, afirma o papel da cooperação penal como um instrumento para aprofundar o processo de integração, bem como reconhece a gravidade das atividades criminosas transnacionais e a dificuldade que pode surgir para a condução de investigações diante da existência de provas situadas em diferentes Estados. ${ }^{31}$

Esse instrumento tem por objetivo eliminar as barreiras burocráticas impostas pelas prerrogativas estatais, de modo a constituir um mecanismo de cooperação penal direta, no âmbito do Mercosul. 
O Protocolo de São Luis, assim como a Convenção de Nassau, fomentam a assistência mútua em matéria penal e possuem mecanismos interessantes, tais como o dever de prestar assistência independente de haver dupla incriminação ${ }^{32}$, mas que não substituem ou simplificam o processo de extradição. Ressalta-se, por fim, que os dois documentos colocam a assistência não como uma faculdade, mas como um dever.

Ademais, em conformidade ainda com a ideia dos dois documentos supra mencionados, encontra-se o Acordo sobre Extradição entre os Estados Partes do Mercosul, de 1998, donde destaca-se ser, em regra, possível extraditar nacionais, ressalvadas as hipóteses em que existe disposição constitucional contrária. Nesse caso, o Estado que denegar a extradição ao requerente deverá promover o julgamento do indivíduo, informar periodicamente sobre o andamento processual e remeter cópia da sentença proferida. ${ }^{33}$

Cumpre ainda falar um pouco do Mandado de Captura do Mercosul, inspirado no Mandado de Detenção Europeu. Trata-se de um instrumento para simplificar o procedimento de extradição tradicional no âmbito mercosulino, incluindo os Estados associados ${ }^{34}$, como ocorre com o correspondente da União Europeia.

A definição do mandado de captura é bem similar à do mandado de detenção europeu. Consiste em uma decisão judicial que determina a entrega de uma pessoa para responder a uma ação penal em curso ou para cumprir pena. Há, contudo, diferenças entre os dois institutos, como o fato de o Acordo relativo ao Mercosul ser bem mais restrito, já que apenas estão abrangidos os crimes contidos em convenções internacionais ratificadas pelo Estado emissor e pelo Estado executor do mandado. ${ }^{35}$ A regra aplicável aos crimes comuns continua sendo os Acordos sobre Extradição vigentes entre os Estados, como o Acordo de Extradição entre os Estados Partes do Mercosul, ou tratados bilaterais sobre o assunto.

Destacados quais os principais diplomas legais que regulam a cooperação judiciária em matéria penal entre os países do Mercosul, cumpre trazer à tona os mais tradicionais instrumentos da cooperação e como eles são usados quando solicitada a cooperação com base nos textos legais existentes e aqui apresentados.

O primeiro instrumento a que se faz menção é a Carta Rogatória, um dos mecanismos mais antigos de cooperação jurídica entre Estados, que representa um pedido formal de auxílio para a instrução do processo, feito pela autoridade judiciária de um Estado a outro. Segundo ensina Nádia de Araújo ${ }^{36}$, as cartas rogatórias destinam-se ao cumprimento de diversos atos, como citação, notificação e cientificação, denominados ordinatórios ou de mero trâmite; de coleta de prova, chamados instrutórios; e, ainda, os que contêm medidas de caráter restritivo, chamados executórios. É o veículo de transmissão de qualquer pedido judicial, podendo ser de caráter cível ou penal.

Todos os conceitos de carta rogatória deixam expressa a natureza jurisdicional deste instrumento, ou seja, uma comunicação entre órgãos jurisdicionais de Estados diferentes. 
Outra modalidade de cooperação jurídica é a Homologação de Sentença Estrangeira, mediante a qual se confere eficácia em território nacional a decisões judiciais exaradas em solo estrangeiro. Corresponde ao grau máximo de cooperação, pois reconhece a eficácia de uma decisão de outro Estado. É um ato definitivo, que movimenta o aparato coercitivo do Estado requerido sobre o indivíduo a quem é voltada a sentença. ${ }^{37}$

Distingue-se da carta rogatória, pois enquanto esta se presta essencialmente ao reconhecimento e cumprimento de decisões interlocutórias da justiça estrangeira, a homologação se destina ao reconhecimento autônomo da decisão judicial de caráter definitivo. ${ }^{38}$

Em sua obra, Galvão de Souza fez importante levantamento do processo de homologação de sentença entre os membros do Mercosul, quando em comparação com países terceiros:

Outro poderá ser o procedimento para nacionalização, quando esta decisão for oriunda de um dos países que compõe o Mercosul. Isto porque o Protocolo de Las Leñas simplificou bastante o procedimento de homologação de sentença estrangeira no âmbito do Mercosul, permitindo que o procedimento se dê por carta rogatória dirigida por órgão jurisdicional estrangeiro direto ao Superior Tribunal de Justiça, via autoridade central, sem a necessidade de propositura de ação de homologação de sentença estrangeira diretamente no Brasil pela parte interessada.

A simplificação do procedimento de homologação de sentença estrangeira por meio da carta rogatória no âmbito do Mercosul também implica na simplificação dos requisitos formais, especialmente a necessidade de comprovação da autenticidade da decisão e dos documentos que a acompanha, uma vez que este requisito é dispensado no trâmite das cartas rogatórias via autoridade central.

Portanto, no Brasil, a partir do Protocolo de Las Leñas, são dois os procedimentos para homologação de sentença estrangeira, dependendo do país de origem da decisão que pretende ser nacionalizada. Se a decisão é proveniente de um dos Estados Partes do Mercosul, o procedimento pode ser simplificado pela carta rogatória, podendo o interessado iniciar a execução da sentença em seu país de origem, requerendo o juiz da execução, por meio de carta rogatória e via autoridade central, que os atos executórios necessários à continuação do processo possam se realizar no Brasil [...]; se, no entanto, a decisão a ser homologada for de origem estranha ao bloco do Cone Sul, a ação de homologação de sentença estrangeira tem que ser proposta por um dos interessados, junto ao Superior Tribunal de Justiça, observando-se a forma tradicional. ${ }^{39}$

Um terceiro instrumento de cooperação que vale a pena abordar é a Extradição, definida por Celso de Albuquerque Mello como o "ato por meio do 
qual o indivíduo é entregue por um Estado a outro, que seja competente, a fim de processá-lo e puni-lo"40.

A extradição é contemplada em inúmeros tratados internacionais, mas, mesmo na ausência de instrumento internacional, poderá também ser solicitada com base no princípio da reciprocidade.

Toffoli e Cestari ${ }^{41}$ abordam ainda, como instrumento de cooperação, a Transferência de Presos, que consiste na remoção de um indivíduo condenado em um Estado para cumprir pena no território de seu Estado de origem. Tem natureza humanitária, uma vez que pretende contribuir para a reintegração social do apenado junto ao seu ambiente familiar. No mesmo rumo, a Transferência de Processos, apresentada pelos mesmos autores retro e prevista, por exemplo, na Convenção da ONU sobre Crime Organizado. Esse instrumento visa a viabilizar o deslocamento de um procedimento penal, já instaurado na jurisdição de um Estado, para outro Estado também competente para processar e julgar aquele ato sempre que o traslado for benéfico ao trâmite do processo.

Nádia de Araújo ${ }^{42}$, por sua vez, levanta a Informação do Direito Estrangeiro e Pedido de Informações, quando há a cooperação para a informação sobre o direito nacional vigente em um determinado Estado para uso judicial em outro Estado, podendo o pedido ser feito sob a forma judicial ou meramente administrativa. No Mercosul, por exemplo, o Protocolo de Las Leñas prevê que esse tipo de informação pode ser enviada diretamente pela Autoridade Central designada.

Assemelha-se, este último método, ao novel Auxílio Direto, último dos instrumentos a ser analisado e que surgiu diante da necessidade de se criarem mecanismos ainda mais arrojados de colaboração, em especial, porque os modelos clássicos já se mostravam insuficientes.

O auxílio direto é a cooperação efetuada entre Autoridades Centrais de países parte de convenções internacionais, com previsão para essa modalidade de cooperação. Nos dizeres de Loula, é um:

[...] procedimento inteiramente nacional, que começa com uma solicitação de ente estrangeiro para que um juiz nacional conheça de seu pedido como se o procedimento fosse interno. Ou seja, a autoridade ou parte estrangeira fornece os elementos de prova para a autoridade central que encaminha o caso para o MPF (penal) ou AGU (civil) propor a demanda desde o início. ${ }^{43}$

Como se percebe, trata-se de um procedimento inteiramente nacional, desde sua origem ao término. É proposto internamente pelo órgão competente e sujeito ao crivo e julgamento do juiz nacional, mediante um requerimento estrangeiro via autoridade central. Não é, portanto, uma decisão judicial, mas requerimento da parte interessada, seja particular ou autoridade administrativa, que se submeterá à decisão do juiz nacional. 
Explicação mais didática confere Galvão de Souza ao escrever que:

Ao contrário do que ocorre nos mecanismos tradicionais de cooperação, onde o pedido de cooperação enseja apenas um procedimento, o auxílio direto origina obrigatoriamente dois procedimentos. O primeiro deles nasce com o pedido de cooperação lavrado pela autoridade requerente e, após análise e seguimento pelas autoridades competentes, chega às autoridades do país requerido para formar o procedimento internacional do auxílio direto. Em busca do atendimento do pedido, devem tais autoridades buscar o início do procedimento pertinente, que pode ser judicial ou administrativo. Este segundo é um procedimento nacional, portanto. Assim é que o auxílio direto, na verdade, forma-se a partir da junção de dois procedimentos específicos e separados: o procedimento internacional, também chamado genericamente de pedido de cooperação ou pedido de auxílio jurídico (este último especialmente no auxílio direto em matéria penal) e o procedimento nacional. $\mathrm{O}$ procedimento nacional, por sua vez, pode ser um processo administrativo, um incidente processual judicial específico [...] ou uma ação judicial. ${ }^{44}$

O auxílio direto em caráter penal é utilizado, em regra, quando um Estado, a fim de subsidiar procedimento em trâmite em seu próprio território, necessita de providência judicial a ser obtida em outra jurisdição. Como a rapidez na obtenção da prova é indispensável, o auxílio direto se torna o instituto mais adequado para a consecução do pedido. ${ }^{45}$

A grande diferença do auxílio direto para os principais mecanismos de cooperação (carta rogatória e homologação de sentença) consiste em que, no auxílio, não existe nenhuma decisão judicial estrangeira a ser cumprida ou reconhecida. O que existe é a produção de uma decisão que é nacional, apenas provocada pela parte estrangeira.

O surgimento do auxílio direto como forma de cooperação mais versátil e compatível com a era atual foi uma das saídas encontradas para dar vazão à grande demanda de auxílio mútuo entre não somente os membros do Mercosul, mas os Estados de todo o mundo.

Finalmente, como foi aqui analisado, vários são os mecanismos trazidos pelas convenções, acordos e tratados firmados pelos Estados Partes do Mercosul relativos à cooperação judicial em matéria penal. Não obstante, ainda há pontos controversos e suscetíveis de serem aperfeiçoados, como a necessidade de criação de órgãos próprios e específicos para fomentar a cooperação nesta área tão importante para a estabilidade do processo de integração.

\section{CONCLUSÃO}

Balizados pelo respeito às soberanias próprias, assim como à ordem interna, os Estados passaram a se juntar em torno de diferentes formas de in- 
tegração ou cooperação seja por motivos de subsistência ou estratégia militar, a História é repleta de casos em que os países optaram por atuar em conjunto de forma cooperativa.

É de se esperar que a cooperação entre os Estados para combater os delitos que ultrapassam as fronteiras nacionais seja tanto mais complexa quanto maior for o grau de integração entre os países. De outro modo não poderia ser, pois que a complexidade inerente a uma integração mais avançada demanda maior grau de conexão entre diferentes agentes estatais. Assim é que se explica a União Europeia ter um sistema de cooperação judiciária penal mais concatenado que o Mercosul. Afinal, enquanto este último surgiu no início da década de 1990, aquele outro deu seus primeiros passos de grande relevância já em meados do século XX.

Um problema que ainda subsiste é o fato de que, enquanto a criminalidade cresce desmedidamente, o avanço nas formas de cooperação depende das instituições dos diversos Estados. Como ainda são muitas as discrepâncias em matéria constitucional, penal, processual e mesmo policial entre os membros de um mesmo grupo, os avanços em matéria de investigação, persecução e repressão ocorrem de forma tímida.

Soma-se a isso o despreparo dos operadores do direito para lidar com o direito estrangeiro. A tradição, em especial nos países do Mercosul, em se voltar somente à jurisdição interna, torna os juristas cegos frente aos instrumentos externos e internacionais, o que atabalhoa de forma flagrante as possibilidades de cooperação.

Da mesma forma, a inflação legislativa com a adoção de distintas normas e atos jurídicos e/ou administrativos sobre o assunto contribui para que o sistema de cooperação internacional seja ainda tão falho. Nos dois grupos estudados, mas em especial no sul americano, as legislações que regulam o tema são esparsas e com grande interstício temporal entre elas. A falta de um elemento normativo centralizado e contemporâneo às práticas criminais da atualidade dá azo a uma incerteza e a um despreparo consideráveis no tocante à matéria. Vemos que, na União Europeia, os instrumentos de cooperação passam por constantes reformas frente às novéis realidades. $\mathrm{O}$ mesmo não pode ser dito do Mercosul, que ainda se mostra perdido e muitas vezes inerte frente às demandas que se apresentam.

Para se chegar a um modelo de cooperação judiciária penal que possa combater com eficácia a criminalidade transfronteiriça, cada vez mais acentuada, urge a necessidade de um melhor preparo dos operadores do direito, para que tenham condições de manejar de forma adequada os instrumentos internacionais de cooperação.

Também é imperioso que os sistemas de integração, assim como os Estados que os compõem, busquem elaborar um sistema normativo único e abrangente, abarcando as formas de cooperação entre eles. Se assim não se proceder, continuará a viger a ineficiência na concretização da justiça, em decorrência de instrumentos díspares e ainda pouco utilizados, além de antiquados, ligados a necessidades de outrora, sendo que as demandas hodiernas já são outras, muito mais complexas. 


\section{REFERÊNCIAS}

ARAÚJO, Nádia. A importância da Cooperação Jurídica Internacional para a Atuação do Estado Brasileiro no Plano Interno e Internacional. In: Manual de Cooperação Jurídica Internacional e Recuperação de Ativos. Brasília: Artecor Gráfica e Editora Ltda., 2008.

BRASIL. Decreto $\mathbf{n}^{\circ} \mathbf{1 5 4}$ de 26 de junho de 1991. Promulga a Convenção Contra o Tráfico Ilícito de Entorpecentes e Substâncias Psicotrópicas.

. Decreto $\mathbf{n}^{\circ}$ 5.015, de 12 de março de 2004. Promulga a Convenção das Nações Unidas contra o Crime Organizado Transnacional.

. Decreto no 5.687, de 31 de janeiro de 2006. Promulga a Convenção das Nações Unidas contra a Corrupção, adotada pela Assembléia-Geral das Nações Unidas em 31 de outubro de 2003 e assinada pelo Brasil em 9 de dezembro de 2003.

. Decreto $\mathrm{n}^{\circ}$ 6.340, de 3 de janeiro de 2008.Promulga a Convenção Interamericana sobre Assistência Mútua em Matéria Penal, assinada em Nassau, em 23 de maio de 1992, e seu Protocolo Facultativo, assinado em Manágua, em 11 de junho de 1993.

. Decreto $\mathrm{n}^{\circ}$ 6.891, de 2 de julho de 2009.Promulga o Acordo de Cooperação e Assistência Jurisdicional em Matéria Civil, Comercial, Trabalhista e Administrativa entre os Estados Partes do Mercosul, a República da Bolívia e a República do Chile.

DIZ, Jamile Bergamaschine Mata. Mercosur. Orígen, Fundamentos, Normas y Perspectivas. Curitiba: Juruá Editora, 2011.

ESTRASBURGO. 20 de abril de 1959. Convention Europeénne d'Entraide Judiciarie en Matière Pénale.

Terrorisme.

27 de janeiro de 1977. Convention Européene pour la Répression du

FOZ DO IGUAÇU. 16 de dezembro de 2010. MERCOSUL/CMC/DEC. No 48/10. Acordo sobre Mandado Mercosul de Captura e Procedimentos de Entrega entre os Estados Partes do Mercosul e Estados Associados.

FRANÇA. Lei $\mathbf{n}^{\circ}$ 57-1426 de 31 de dezembro de 1957. Institui o Código de Processo Penal Francês.

JOANNIN, Pascale. Le casier judiciaire européen: quelles perpectives? Paris. Fondation Robert Schuman, 2006. Disponível em: <http://www.robert-schuman.eu/ $\mathrm{fr} /$ questions-d-europe/0019-le-casier-judiciaire-europeen-quelles-perspectives $>$. Acesso em: mar. 2014.

KLUG, Augusta Carla. A extradição de nacionais entre Estados-Membro da União Europeia. Florianópolis: UFSC, 2009. 
LUXEMBURGO. 2002/584/JAI: Decisão-quadro do Conselho, de 13 de Junho de 2002, relativa ao mandado de detenção europeu e aos processos de entrega entre os Estados-Membros - Declarações de alguns Estados-Membros quando da aprovação da decisão-quadro.

MARIANO, Marcelo Passini; MARIANO, Karina L. Pasquariello. As teorias de integração regional e os Estados subnacionais. Impulso. Piracicaba, Ed. Unimep, 2012, v. 13, n. 31, pp. 1-179.

; MARTINS, Thiago Penido. A integração interestatal e as transformações nos elementos essenciais para a definição de Estado. In: Anais do XXIV Congresso do Conselho Nacional de Pós-graduação e Pesquisa em Direito CONPEDI. Aracaju, 2015 (no prelo).

NICE. 26 de fevereiro de 2001. TRATADO DE NICE que altera o Tratado da União Europeia, os tratados que instituem as Comunidades Europeias e alguns atos relativos a esses tratados.

PARIS. 13 de dezembro de 1957. Convention Européene d'Extradition.

ROMA. 04 de novembro de 1950. Convenção Europeia dos Direitos do Homem.

SERVICE du Casier Judiciaire National. Le casier judiciare. Nantes: France Diplomatie, 2013. Disponível em: http://www.diplomatie.gouv.fr/fr/adopter-a-l-etranger/comment-adopter-a-l-etranger/les-fiches-pratiques-pour-adopter/ article/le-casier-judiciaire. Acesso em março de 2014.

SOUZA, Gustavo Henrique Galvão de. A cooperação jurídica no Mercosul: análise das cartas rogatórias trocadas entre Brasil e Uruguai e o papel do superior tribunal de justiça. Montevidéu: Universidad de la Empresa, 2014.

TOFFOLI, José Antônio Dias; CESTARI, Virgínia Charpinel Junger. Mecanismos de Cooperação Jurídica Internacional no Brasil. In: Manual de Cooperação Jurídica Internacional e Recuperação de Ativos. Brasília: Artecor Gráfica e Editora Ltda, 2008.

TROTTA, Sandro Brescovit; FERREIRA, Luciano Vaz. Cooperação jurídica internacional em matérias penal: contornos históricos. Sistema Penal \& Violência. Porto Alegre: Pontifícia Universidade Católica do Rio Grande do Sul, janeiro-junho 2013, v. 5, n. 1, p. 1-14.

VENANCIO, Daiana Seabra. Mercosul e o Combate à Criminalidade Transnacional: um Estudo dos Instrumentos de Cooperação Judiciária em Matéria Penal. In: Seminário Brasileiro de Estudos Estratégicos Internacionais, 2013, Porto Alegre. Anais 2013, Porto Alegre: UFRGS, 2013. 
1 TOFFOLI, José Antônio Dias; CESTARI, Virgínia Charpinel Junger. Mecanismos de Cooperação Jurídica Internacional no Brasil. In: Manual de Cooperação Jurídica Internacional e Recuperação de Ativos. Brasília: Artecor Gráfica e Editora Ltda, 2008, p. 23.

2 SOUZA, Gustavo Henrique Galvão de. A cooperação jurídica no Mercosul: análise das cartas rogatórias trocadas entre Brasil e Uruguai e o papel do superior tribunal de justiça. Montevidéu: Universidad de la Empresa, 2014, p. 37.

3 ABIMORAD, Leonardo Araújo. A cooperação judiciária de direito internacional como fórmula para resolver conflitos entre particulares no Mercosul, apud SOUZA, loc. cit.

4 DIZ, Jamile Bergamaschine Mata. Mercosur. Origen, Fundamentos, Normas y Perspectivas. Curitiba: Juruá Editora, 2011, p. 29.

5 MARIANO, Marcelo Passini; MARIANO, Karina L. Pasquariello. As teorias de integração regional e os Estados subnacionais. Impulso. Piracicaba, Ed. Unimep, 2012, v. 13, n. 31, pp. 1-179, p. 50.

6 DIZ, Jamile Bergamaschine Mata; MARTINS, Thiago Penido. A integração interestatal e as transformações nos elementos essenciais para a definição de Estado. In: Anais do XXIV Congresso do Conselho Nacional de Pós-graduação e Pesquisa em Direito - CONPEDI. Aracaju, 2015 (no prelo).

7 A RJE é, por sua vez, um instrumento que permite o conhecimento jurídico regional, podendo ser utilizado pelos estrangeiros para, por exemplo, identificar as autoridades locais competentes para receber uma carta rogatória.

8 KLUG, Augusta Carla. A extradição de nacionais entre Estados-Membro da União Europeia. Florianópolis: UFSC, 2009, p. 21.

9 Ibid., p. 26.

10 Como sugere o nome, o Princípio da Dupla Incriminação estabelece que a extradição só poderá ser concedida para fatos punidos tanto na legislação do Estado requerente, quanto do Estado requerido.

11 KLUG, op. cit., p. 29.

12 A expressão é tradução livre do termo francês "casier judiciaire européen", mas poderia ser adotada também a tradução como "ficha criminal europeia".

13 Tratar-se-ia de um registro criminal informatizado em que são inscritas as condenações penais. Ficaria incumbido de centralizar e conservar todas as condenações penais contra uma pessoa.

14 PASCALE, op. cit.

15 Ibid.

16 Ibid.

17 Ibid.

18 ARAÚJO, Nádia. A importância da Cooperação Jurídica Internacional para a Atuação do Estado Brasileiro no Plano Interno e Internacional. In: Manual de Cooperação Jurídica Internacional e Recuperação de Ativos. Brasília: Artecor Gráfica e Editora Ltda., 2008, p. 42.

19 VENANCIO, Daiana Seabra. Mercosul e o Combate à Criminalidade Transnacional: um Estudo dos Instrumentos de Cooperação Judiciária em Matéria Penal. In: Seminário Brasileiro de Estudos Estratégicos Internacionais, 2013, Porto Alegre. Anais 2013, Porto Alegre: UFRGS, 2013, p. 4.

20 O primeiro passo para a sua formação ocorreu em 1997 com a criação do Centro Internacional para a Prevenção do Crime (CICP) como parte do Escritório das Nações Unidas sobre Drogas e Crime (UNODC). Em 1988, por determinação da Resolução no 53/111, da Assembleia Geral das Nações Unidas, o comitê de trabalho para elaborar uma convenção internacional de combate à criminalidade transnacional foi instituído. Em 1999, em Palermo (Itália), houve conferência para a análise do texto preparado por esse comitê, sob o título de Convenção das Nações Unidas contra o Crime Organizado Transnacional, que ficou conhecida como Convenção de Palermo. Finalmente, na Assembleia Geral do Milênio, em 15 de novembro de 2000, na cidade de Nova York, a Convenção foi adotada pelas Nações Unidas, entrando em vigor aos 29 de setembro de 2003.

21 Os instrumentos mais comuns com que são feitos os pedidos de cooperação serão apresentados em um momento posterior no presente trabalho.

22 VENANCIO, op. cit., p. 04.

23 Todas as Convenções e Protocolos até então trabalhados estão em vigor entre os países do Mercosul, de maneira que fazem parte dos instrumentos de cooperação judiciária em matéria penal.

24 TROTTA, Sandro Brescovit; FERREIRA, Luciano Vaz. Cooperação jurídica internacional em matérias penal: contornos históricos. Sistema Penal \& Violência. Porto Alegre: Pontifícia Universidade Católica do Rio Grande do Sul, janeiro-junho 2013, v. 5, n. 1, pp. 1-14, p. 12.

25 Ibidem., p.13. 
26 VENANCIO, op. cit., p. 06.

27 Ibidem.

28 TROTTA; FERREIRA, op. cit., p. 09.

29 CERVINI, Raul; TAVARES, Juarez. Princípios de Cooperação Judicial Penal Internacional no Protocolo do Mercosul. São Paulo: Revista dos Tribunais, 2000, p. 88, apud TROTTA; FERREIRA, loc. cit.

30 TROTTA, Sandro Brescovit; FERREIRA, Luciano Vaz. Cooperação jurídica internacional em matérias penal: contornos históricos. Sistema Penal \& Violência. Porto Alegre: Pontifícia Universidade Católica do Rio Grande do Sul, janeiro-junho 2013, v. 5, n. 1, pp. 1-14, p. 9.

31 VENANCIO, op. cit., p. 7.

32 Cf. art. $5^{\circ}$ da Convenção Interamericana sobre Assistência Mútua em Matéria Penal e art. $1^{\circ}$, item 5 do Protocolo de Assistência Jurídica Mútua em Assuntos Penais.

33 VENANCIO, op. cit., p. 8.

34 Ainda não houve, contudo, ratificação do Acordo por nenhum Estado, não existindo previsão para que entre em vigor.

35 VENANCIO, op. cit., p. 9.

36 ARAÚJO, op. cit., p. 43.

37 SOUZA, op. cit., p. 45.

38 TOFFOLI; CESTARI, op. cit., p. 25.

39 SOUZA, Gustavo Henrique Galvão de. A cooperação jurídica no Mercosul: análise das cartas rogatórias trocadas entre Brasil e Uruguai e o papel do superior tribunal de justiça. Montevidéu: Universidad de la Empresa, 2014, p. 45.

40 MELLO, Celso D. de Albuquerque. Direito Constitucional Internacional. Rio de Janeiro: Renovar, 1994, p. 169, apud TOFFOLI; CESTARI, Loc. cit.

41 TOFFOLI; CESTARI, op. cit., p. 26.

42 ARAÚJO, op. cit., p. 45.

43 LOULA, Maria Rosa. Auxílio Direto em Matéria Civil: Novo Instrumento Brasileiro de Cooperação Jurídica Internacional. Tese (Doutorado em Direito) - Universidade do Estado do Rio de Janeiro, 2007, apud ARAÚJO, Nádia. A importância da Cooperação Jurídica Internacional para a Atuação do Estado Brasileiro no Plano Interno e Internacional. In: Manual de Cooperação Jurídica Internacional e Recuperação de Ativos. Brasilia: Artecor Gráfica e Editora Ltda., 2008, p. 45.

44 SOUZA, op. cit.

45 TOFFOLI; CESTARI, op. cit., p. 27.

\title{
JUDICIAL CRIMINAL COOPERATION AND REGIONAL INTEGRATION: REGULATORY AND INSTITUTIONAL TREATMENT IN THE EUROPEAN UNION AND MERCOSUR
}

\begin{abstract}
It has long been noted that a country that acts alone in the world is bound to plunge into crisis that are avoidable through an integrated action of the various international actors. Among the issues that arise in today's global spectrum, there are those that reach the criminal sphere across borders. On this track, this study seeks to make a comparative survey of criminal judicial cooperation mechanisms within the European Union and Mercosur, as well. With the growth of levels of integration, there was
\end{abstract}


an increase in the exchange of people, goods and services, aligned to the progressive abolition of borders, which brought undesired growth of cross-border crime. Thus, countries that make up an integration system were forced to adopt convergent policies to crack down interstate crimes and prevent impunity. The conclusion reached is that, despite the significant progress already made, the instabilities and discrepancies between members of the same process of integration prevent more effective cooperation, which is a serious problem, given the rising in transnational crime.

Keywords: Integration. Penal Cooperation. Mercosur. European Union.

Submetido: 19 out. 2015

Aprovado: 5 jan. 2016 